\title{
LA ENSEÑANZA DE LOS TEXTOS DEPORTIVOS. ESTUDIO DE LAS PORTADAS IMPRESAS DE ESPAÑA Y PORTUGAL ${ }^{1}$
}

\author{
Sergio Suárez Ramírez \\ Universidad de Valladolid \\ Ângela Balça ${ }^{2}$ \\ Universidade de Évora/CIEC (Portugal) \\ Paulo Costa \\ Universidade de Évora/CIEP (Portugal)
}

\begin{abstract}
RESUMEN: En la sociedad actual, con Internet, hay infinidad de textos. Por eso resulta necesario seleccionar los más atractivos para el alumnado con el objetivo de fomentar el gusto por la lectura. Este trabajo analiza durante una semana cada uno de los enunciados que aparecen en las portadas de los periódicos deportivos de España (As, Marca, Mundo Deportivo y Sport) y Portugal ( $A$ Bola, O Jogo y Record). Con su análisis se pretende demostrar que la mayoría de los enunciados son retóricos, y que esto ocurre en ambos países. Se ha optado por los periódicos deportivos porque despiertan interés, y resulta un tema conocido para los más jóvenes. No hay que olvidar que los textos deportivos son tan creativos como los publicitarios (Guerrero Salazar, 2007). A través de una propuesta didáctica concreta se muestra cómo trabajar con títulos tan sugerentes como "Por todo lo alto" (Marca) y “¡Mamma mia!! $(M D)$ o "Aviso Amarelo" ( $A$ Bola) o "Dragão à prova de ressaca" (O Jogo) para enseñar a escribir con la expresividad y emotividad. Requisitos que toda creación literaria necesita para tener éxito, para ser atractivo para los lectores.

PALABRAS CLAVE: Periódicos deportivos, creatividad literaria, animación lectora, didáctica de la lengua y la literatura, educación obligatoria.
\end{abstract}

1. Los periódicos portugueses son "A Bola", "O Jogo" y "Record". Los españoles son "As", "Marca", "Mundo Deportivo" y "Sport".

2. Este Trabalho foi financiado por Fundos Nacionais através da FCT - fundação para a Ciência e Tecnologia) e cofinanciado pelo Fundo Europeu de Desenvolvimento Regional (FEDER) através do COMPETE 2020 - Programa Operacional Competitividade e Internacionalização (POCI) no âmbito do CIEC (Centro de Investigação em estudos da Criança da Universidade do Minho) com a referênciaPOCl-01-0145FEDER-007562.

3. Este trabalho é financiado por fundos nacionais através da FCT - Fundação para a Ciência e a Tecnologia, I.P., no âmbito do projeto UID/CED/04312/2016. (CIEP - Centro de Investigação em Educação e Psicologia - Universidade de Évora). 


\title{
TEACHING THROUGH SPORTS TEXTS. STUDY OF NEWSPAPERS COVERS IN SPAIN AND PORTUGAL
}

\begin{abstract}
In actual society, with Internet, there are countless texts. For that it is important to select the most attractive for students with the objective of improve the love for reading and writing. This article analyzes, during a week, the first page of seven sports newspapers in Spain and Portugal to show that can be really easy to find attractive and rethoric texts as educative tools in the two countries. Sport newspapers have been chosen as study object because they are interesting for students, because its familiar topic for young people. It should not be forgotten that sport texts are as creative as the advertising ones (Guerrero Salazar, 2007). Through a concrete activities it is shown how professors can use texts as suggestive like "Por todo lo alto" (Marca), "Mamma mia" (Mundo Deportivo), "Aviso Amarelo" ( $A$ Bola) or "Dragão à prova de ressaca" ( $O$ Jogo) to teach the relevant use of rethoric when students have to write different texts. Rhetoric can serve to make succesful texts become them in attractive and creative ones for readers.

KEYWORDS: Sport newspapers, teaching creative writing, motivation in reading, Didactic in language and literature, obligatory education.
\end{abstract}

Recibido: 01/06/2017

Aceptado: 30/10/2017

Correspondencia: Sergio Suárez Ramírez, Universidad de Valladolid, Campus Universitario Miguel Delibes, Paseo de Belén, 1, 47011 Valladolid. Email: sergio.suarez@uva.es.

\section{INTRODUCCIÓN}

Vivimos en un mundo mediatizado y digital (sociedad de la información) donde Internet y las tecnologías de la información y comunicación (TIC), y del aprendizaje y del conocimiento (TAC), nos ofrecen el acceso a miles de textos online. En España los usuarios leen y consumen noticias (textos periodísticos) con una frecuencia alta, porque también pueden consultarlas a través de los dispositivos de bolsillo ${ }^{4}$. Y en Portugal la situación es similar: el número de teléfonos móviles por ciudadano se ha disparado y en 2011 se situaba en 20 millones de estos dispositivos de bolsillo (cuando la población de Portugal es de 10.5 millones de personas) ${ }^{5}$. Gracias a las TIC/TAC hay más lugares donde leer y donde ser creador de contenidos y textos.

Entre todos los enunciados que aparecen en un diario, los titulares son lo primero que los lectores leen, el más alto nivel de la macroestructura informativa (Van Dijk,

4. Estudio de la Asociación para la Investigación de los Medios de Comunicación (AIMC), encuesta "Usuarios de Internet", informe de marzo de 2017. Disponible en línea (consultado el 03/2017).

5. Datos extraídos de la base PORDATA, Base de Dados de Portugal Contemporáneo (Marzo de 2017). Disponible online (fecha de consulta: mayo de 2017): http://www.pordata.pt/Portugal/Assinantes+ ++equipamentos+de+utilizadores+do+servi $\% \mathrm{C} 3 \% \mathrm{~A} 7 \mathrm{o}+\mathrm{m} \% \mathrm{C} 3 \% \mathrm{~B} 3 \mathrm{vel}-1180$. 
1990). Resulta esencial recuperar esta cita para definir lo que está pasando en una sociedad mediática y digital como la actual. Cientos de textos nos invaden, pero se leen los más cortos y breves por el ritmo en el que se vive. Esta velocidad y ritmo de vida impide una lectura reflexiva de los textos digitales (Carr, 2011). Por eso, es necesario que se escriban textos atractivos, expresivos, emotivos, que animen a la lectura y que sean ejemplos de creatividad literaria.

En los periódicos digitales encontramos todos estos ingredientes: emotividad, expresividad, creatividad, brevedad... por eso, son útiles en el proceso de enseñanzaaprendizaje. Como docentes, se puede enseñar lengua y literatura a través de enunciados tan sugerentes como "Por todo lo alto" (Marca), “¡Mamma mia!! (MD), "Respeto y alivio" (Sport), o "Bayern-Real Madrid: Un trueno para cuartos" (AS), ejemplos extraídos de los cuatro principales periódicos deportivos de España o de los tres más vendidos en Portugal como "Aviso Amarelo" ( $A$ Bola), "Dragão à prova de ressaca" (O Jogo) o "Pizzi e mais 10" (Record), todos extraídos de las portadas el día 18 de marzo de 2017. Al recurrir a un lenguaje expresivo y emotivo resultará más ameno y fácil trabajar con textos. El fenómeno deportivo también añade un componente de espectacularidad que ayuda y motiva en el aprendizaje.

\section{Estado de la cuestión}

Los medios de comunicación permiten comprender mejor lo que ocurre a nuestro alrededor (McLuhan, 1974). Su misión divulgadora es muy útil en el ámbito educativo, ya que reúnen temas para todos los gustos. Son claves para que los alumnos conozcan y reflexionen sobre lo que ocurre fuera del aula, porque sirven de ventana al mundo (Cuvardiac y Vargas, 2007) y para fomentar el pensamiento crítico (Caldas, 2006). Además, resultan interesantes porque, en los textos de los periódicos hay "un nido de lenguajes" como el político, administrativo, literario, coloquial (Martínez Hernando, 1990). En ellos encontramos la presencia del habla fusionada con la escritura (Oliva, 2012); son el principal lugar de nacimiento de nuevas palabras (Alvar Ezquerra, 1994). Con el uso de las TIC/TAC es más fácil sentirse un poco periodista, porque hay más espacios y lugares donde escribir, donde hablar, donde interaccionar, comunicar y/o compartir. En el proceso comunicativo parece más fácil emitir que recibir, por la cantidad de posibilidades que nos ofrece la tecnología.

Es importante reflexionar sobre el papel que juegan los medios de comunicación en las aulas, porque la sociedad mediática y digital los necesita como herramientas de enseñanza. Entre sus muchas posibilidades didácticas es destacable su uso para: (1) creación literaria de murales; (2) identificación y diseño de las letras; (3) contenidos gramaticales diversos; (4) desarrollo de la expresión escrita manual y tipográfica; (5) generación de debates y entrevistas para fomentar el diálogo y compañerismo en el aula; (6) búsqueda y selección de información a través de distintas aplicaciones favoreciendo el uso de distintos dispositivos; (7) conocimiento de distintos textos periodísticos, su tipología, estructura y características; (8) aproximación a recursos estilísticos que sirven para emocionar y apelar a la atención del receptor como el tono, volumen y duración de los mensajes de audio; (9) identificación e imitación de gestos, miradas y posturas corporales a través de las imágenes audiovisuales o de programas de televisión; (10) producción y divulgación de textos y multimedia elaborado por el alumnado a través de las TIC/TAC. 
Muchos autores han recomendado el uso de los medios de comunicación desde distintos enfoques: la radio en la escuela (Jiménez Martínez, 2001; Assumpçao, 1999); para abordar la historia o la cultura (Ayala Payet, 1994); por las posibilidades didácticas de su lenguaje (Quintana Garzón, 2001); las imágenes de la televisión en la etapa de Infantil (LaCalle, 1997) o los desafíos que representan para la escuela (Morán, Masetto y Behrens, 2006), o cómo construir un periódico escolar (Freinet, 1974), la aplicación didáctica de fotografías y noticias de la prensa impresa (Suárez Muñoz, 1992), el potencial de Internet para trabajar el periodismo en la escuela (Fidalgo, 2000) o cómo crear un periódico en el aula (Martín Vegas, 2009); por citar algunos ejemplos y autores.

Los alumnos se muestran motivados para aprender con los textos familiares y cercanos, que consultan en su tiempo libre, leen en su casa o en cualquier lugar y que pueden compartir con sus amigos en cualquier momento. El impulso adquirido en los últimos años por los periódicos digitales ${ }^{6}$ junto con la, cada vez mayor, presencia de los dispositivos electrónicos, con un precio asequible para los jóvenes, ha posibilitado que el uso de este tipo de prensa sea idóneo para la enseñanza. Los datos del último informe de la Asociación para la Investigación de los Medios de Comunicación (AIMC) demuestran que una de las actividades preferidas por los usuarios es consultar noticias. Las TIC/TAC resultan familiares y cercanas, y permiten el acceso a contenidos de cualquier lugar del mundo. Internet, por su parte, ofrece una nueva forma de Ilevar el periódico al aula. Una forma accesible, gratuita y ubicua que no se debe pasar por alto. Entre todos los medios de comunicación, el periódico es el que más se ha beneficiado del soporte digital -convergencia de medios- (Salaverría, 2005). Incluso, algunos autores han asignado un nombre a estos medios de comunicación: Ios cibermedios (Salaverría y Díaz, 2003). A través de ellos también es posible consultar la portada impresa del periódico, basta con buscar y explorar el sitio web de su versión digital. En cualquier caso, y sea cual sea su soporte -impreso o digital-, el periódico será siempre "un estímulo muy importante para la enseñanza de contenidos curriculares, sobre todo del área de lengua y literatura" (Suárez Muñoz, 1992: 13). Por eso conviene, desde el punto de vista didáctico, aprovechar su uso para diseñar actividades con un orden y una metodología precisa, también lúdica y práctica que sirva para entender los textos, enamorarse de ellos para, después, crearlos. Con el uso de textos extraídos de Internet y la selección de una temática como hilo argumental de las actividades que sea atractiva para el alumnado, este se sentirá motivado en su aprendizaje. Es preciso favorecer el sentido crítico del alumnado para fomentar su creatividad literaria.

Los datos indican que el uso de Internet va en aumento. La tendencia es que los docentes seleccionen textos online. De hecho, según los datos del Observatorio Nacional de las Telecomunicaciones y la Sociedad de la Información del Gobierno español, cada vez hay más hogares con conexión a Internet ${ }^{7}$. Una sociedad en permanente conexión,

6. En el informe de la AIMC, anteriormente referido, la lectura de noticias es la primera actividad que realizan los usuarios en Internet (más del 85\%) mientras que la visualización de vídeo ocupa el segundo lugar (84,4\%). Los datos se refieren al comportamiento de usuarios españoles.

7. Los datos de este informe demuestran una progresión en el uso de Internet en los hogares españoles (del 33\% de 2004 se pasa a más del 74\% en 2014). Observatorio Nacional de las Telecomunicaciones y de la Sociedad de la Información. Gobierno de España. 
al igual que ocurre en Portugal. Los hogares portugueses se conectan más que hace quince años: del 26,9\% de los portugueses de 2002 se ha pasado al $71 \%$ en $2015^{8}$.

Después de resaltar la importancia de usar los medios de comunicación en el aula y de las tendencias que nos sugieren los informes sobre el uso de Internet y de TIC/ TAC entre los españoles y portugueses, es necesario escoger una temática familiar y cercana para los jóvenes, para motivar el aprendizaje de la lengua y la literatura. Esa temática es el deporte.

El lenguaje deportivo es un espectáculo idiomático (Castañón Rodríguez, 2006b), lugar de creación de nuevas palabras (Alvar Ezquerra, 1994). Incluso, se sitúa entre los más creativos que existen. Un claro ejemplo es la jerga futbolística (Lázaro, 1994). El deporte sigue siendo un fenómeno social de gran alcance (Hernández Alonso, 2003) y se ha convertido en toda una "epopeya de nuestro tiempo" (Alvar Ezquerra, 1994: 186).

Entre todas las informaciones que recogen los medios de comunicación hay una que genera un volumen informativo sin igual (Alcoba, 2005). Si genera ese volumen, será porque la sociedad lo demanda. De hecho, cada vez son más los autores que reclaman que el deporte sea hilo conductor de distintos contenidos didácticos (Rodeselier, 2016; Galindo, 2016). El deporte es el elemento que define la historia contemporánea, es una industria de ocio y una necesidad social (Castañón, 2006a), un fenómeno que moldea comportamientos y sentimientos al tiempo que refuerza los valores y estructuras de la sociedad (Brandão, 1996). La cultura deportiva está presente en la vida de muchos estudiantes (Rodeselier, 2016), no conoce fronteras, es universal. Todos ellos son elementos que forman una base importante para la enseñanza de cualquier lengua, porque el deporte nos remite a un conocimiento común compartido, algo que nos une y supera fronteras. Además, trata de un aspecto de la actividad humana que, siempre en términos generales, puede interesar a una buena parte de la sociedad. El interés por este tema es un factor positivo añadido, por eso conviene que el deporte sea el tema central de los textos que se utilicen en la enseñanza.

El fútbol, considerado como el deporte rey, y el resto de disciplinas deportivas sirven de gancho y motivación para muchos lectores que no solo practican deporte, sino que demandan y muestran interés por la temática deportiva y saludable. Galindo (2016) sugiere que el deporte sea un tema abordado en las clases de español como lengua extranjera, porque el Marco Común Europeo de Referencias de las Lenguas (2002) incluye al deporte entre una de sus áreas temáticas relacionadas con la cultura. El deporte es, en definitiva, una fuente inagotable de noticias (Medina, 1995). La propuesta que aquí se presenta, parafraseando a este autor, invita a convertir el deporte en una fuente inagotable de recursos didácticos.

Hay que recordar, como sugiere Sitman (2003), que la prensa deportiva, por su claridad, concisión, brevedad, actualidad y proximidad a la oralidad, es muy interesante para su aprovechamiento didáctico, en una clase de lengua y literatura, por ejemplo.

8. Datos actualizados hasta noviembre de 2016. Disponible en Internet (consultado en mayo de 2017): http://www.pordata.pt/Portugal/Agregados+dom $\%$ C3\%A9sticos+privados+com+computador++CO $\mathrm{m}+$ liga $\% \mathrm{C} 3 \% \mathrm{~A} 7 \% \mathrm{C} 3 \% \mathrm{~A} 3 \mathrm{O}+\% \mathrm{C3} \% \mathrm{~A} 0+$ Internet+e+com+liga $\% \mathrm{C} 3 \% \mathrm{~A} 7 \% \mathrm{C} 3 \% \mathrm{~A} 3 \mathrm{O}+\% \mathrm{C} 3 \% \mathrm{~A} 0+$ Internet+a trav\%C3\%A9s+de+banda+larga+(percentagem)-1158. 
En los textos deportivos, como recuerda García (2002), aparecen unas expresiones tan sugerentes que se asumen y pasan a emplearse en nuestra vida cotidiana, en el ámbito escolar o dentro de la familia, como "casarse de penalti [o] sufrir un golpe bajo" (García, 2002: 17).

La belleza y creatividad de los textos deportivos está presente en expresiones que asemejan el césped del estadio a un verde tapiz, cuando se relata el gol como una bella factura, o al nombrar a los jugadores como extremos o delanteros natos (Lázaro, 1994).

Es importante la observación, selección y posterior análisis de estos textos para conocer cómo los periodistas redactan textos y titulares creativos que emocionan a los lectores y cuáles son las palabras que usan para cumplir esa finalidad informativa, apelativa y expresiva/emotiva. Aunque son textos escritos, su estilo tiene mucho que ver con el discurso oral cotidiano. Simplemente basta fijarse en alguna expresión o palabra que la sociedad ha aceptado (por ejemplo, referirse a Cristiano Ronaldo como "El bicho" o decir que Messi es "el Messías"), porque muchos de los términos deportivos suenan familiares, cotidianos. Por ello, resulta fundamental seleccionar textos que sirvan para diseñar buenos escritos, a través de palabras que tengan la capacidad de emocionar a los lectores. Esta cualidad es fácilmente reconocible en los textos deportivos. Evidentes ejemplos de estilo y ornamentación en el texto para que el alumnado sepa reconocerlo y aplicarlo.

Los textos deportivos tienen un estilo peculiar porque están basados en el arte de la persuasión. El deporte es "un área peculiar, de gran seguimiento y con gran carga de emotividad" (Sobrados, 2005: 185). Si a esto unimos que el alumnado los considera textos familiares, cercanos al habla cotidiana y accesibles a través de los dispositivos tecnológicos. Con estas concepciones es fácil entender su idoneidad como tema motivante para trabajar distintos contenidos del área de lengua y literatura.

Persuadir o sugerir son acciones y objetivos que debe buscar cada escritor con su texto, por eso es importante enseñar cómo hacerlo. "El núcleo de la retórica es la persuasión", afirma Knapé (2003: 876). El diccionario de la Real Academia Española define persuadir como la acción de "inducir, mover u obligar a alguien con razones a creer o hacer algo". Mientras que sugerir es "proponer o aconsejar algo" o "evocar algo y hacer pensar en ello". Para persuadir, sugerir, provocar o convencer es importante pensar en la retórica, porque es inseparable de la comunicación (Albadalejo, 2005). Por eso, hay autores que afirman que los medios de comunicación han dado lugar a la resurrección de la retórica (García Gallardo, 1994). La finalidad de todo discurso es, como decían los romanos, enseñar, deleitar y mover a la acción -docere, delectare, movere-. El arte del discurso (y del texto) está en que sea retórico.

En una sociedad digital donde el número de textos accesibles es ingente e inabarcable, hay que ser creativos y enseñar a diseñar enunciados con un fin sugestivo, persuasivo y festivo. El adorno del texto mediante el uso de las figuras retóricas "condiciona de una manera especial la recepción del mensaje" (Guerrero, 1999: 465). Esto también sucede cuando combinamos distintas palabras para crear un juego lingüístico con ellas. Es clave para atraer al lector, que ve en el texto un juego periodístico (Guerrero, 2002), la magia de la combinación y selección de las palabras más apropiadas. 


\section{Método}

La investigación ha consistido en el estudio y cuantificación de una muestra de 593 enunciados repartidos en 49 portadas impresas (7 periódicos deportivos, cuatro de España y tres de Portugal) durante 7 días -una semana- (13 al 19 de marzo de 2017). El objetivo de la investigación es demostrar que la mayoría de los enunciados de las portadas (pueden ser titulares u otro tipo de textos periodísticos) tienen elementos retóricos y, por tanto, son ejemplos creativos y expresivos con los que trabajar en el aula de Lengua y Literatura.

Se ha seleccionado una semana de análisis para resaltar la cantidad de ejemplos y materiales que se pueden encontrar en estos periódicos y en sus portadas en tan breve periodo de tiempo ${ }^{9}$. Esta circunstancia demuestra que puede ser extremadamente fácil para el profesorado utilizar estos recursos y aprovecharlos en cualquier momento del curso.

En cuanto a las fases de la investigación, primero se analizó el número total de enunciados que conforman cada una de las portadas objeto de estudio. Después valoró si en esos enunciados había algún elemento retórico, ya fuera una figura retórica (metáforas, metonimias, hipérboles, epítetos, aliteraciones, personificaciones...) por considerarlas como unidad básica de los recursos expresivos o combinación de elementos lingüísticos o de sentido que provocan un efecto estético y persuasivo en el receptor (Robrieux, 1993).

Para presentar los resultados se ha optado por dos tablas (tablas 1 y 2) donde las siglas ET son los enunciados totales o textos que aparecen en la portada impresa de cada periódico. Es importante precisar que en este estudio se han considerado aquellos textos que aparecen en las portadas y que, por su tamaño, forma o color, se diferencian los unos de los otros. Por eso, no se habla de titulares y sí de enunciados como "secuencia verbal dotada de sentido y sintácticamente completa" (Maingueneau, 1999: 43). Con la denominación de "enunciados" se incluyen, por tanto, los titulares, subtítulos, antetítulos y todo tipo de textos informativos que aparecen en la portada. Solo se excluyen los textos de naturaleza publicitaria.

Las tablas 1 y 2, que presentan los resultados $E R$, identifican los enunciados que son retóricos de entre todos los textos analizados. Para su cuantificación se han considerado elementos retóricos, además de las figuras retóricas, a: (1) las frases hechas, socialmente aceptadas y conocidas que también consiguen Ilamar y captar la atención del lector "Ojo por ojo" o el conocido título de una película: como título de película: "Salvar al soldado..."); y (2) los anglicismos ("Stop", "Ok", "Ko"), por impresionar y sorprender en medios no anglosajones. En definitiva se han tomado en cuenta por ser elementos clave de la fase del elocutio.

Por último, en las tablas 1 y 2 también aparece otro indicador que es el porcentaje de enunciados retóricos totales que aparece en una determinada portada impresa. De esta forma, no solo se cuantifican los enunciados, también se expresa el porcentaje de retórica en proporción al número total de titulares de cada portada.

9. Este trabajo contiene, en los anexos, algunos ejemplos del corpus analizado. 
Tabla 1. Jornais Portugueses. Fuente: elaboración propia

\begin{tabular}{|l|c|c|c|c|c|c|}
\hline \multirow{2}{*}{ DATAS } & \multicolumn{2}{|c|}{$\boldsymbol{A ~ B O L A}$} & \multicolumn{2}{c|}{ O JOGO } & \multicolumn{2}{c|}{ RECORD } \\
\cline { 2 - 8 } & ET & ER & ET & ER & ET & ER \\
\hline SEGUNDA-FEIRA & 14 & 7 & 16 & 11 & 17 & 9 \\
\hline TERÇA-FEIRA & 15 & 6 & 16 & 6 & 12 & 8 \\
\hline QUARTA-FEIRA & 17 & 8 & 9 & 6 & 16 & 9 \\
\hline QUINTA FEIRA & 13 & 5 & 15 & 8 & 13 & 7 \\
\hline SEXTA FEIRA & 15 & 9 & 15 & 8 & 15 & 10 \\
\hline SABADO TOTAL & 19 & 9 & 13 & 13 & 13 & 9 \\
\hline DOMINGO & 14 & 7 & 15 & 11 & 14 & 10 \\
\hline \multicolumn{2}{|c|}{$\mathbf{1 0 7}$} & $\mathbf{5 1}$ & $\mathbf{9 9}$ & $\mathbf{6 3}$ & $\mathbf{1 0 0}$ & $\mathbf{6 2}$ \\
\hline $\begin{array}{c}\text { Porcentaje de retórica } \\
\text { en los enunciados }\end{array}$ & $\mathbf{4 7 , 6 \%}$ & \multicolumn{2}{|c|}{$\mathbf{6 3 , 6 \%}$} & \multicolumn{2}{|c}{$\mathbf{6 2 \%}$} \\
\hline
\end{tabular}

ET: enunciados totales.

ER: enunciados retóricos o persuasivos.

Tabla 2. Periódicos españoles. Fuente: elaboración propia

\begin{tabular}{|c|c|c|c|c|c|c|c|c|}
\hline \multirow[t]{2}{*}{ FECHAS } & \multicolumn{2}{|c|}{$A S$} & \multicolumn{2}{|c|}{$M A R C A$} & \multicolumn{2}{|c|}{$\begin{array}{c}\text { MUNDO } \\
\text { DEPORTIVO }\end{array}$} & \multicolumn{2}{|c|}{ SPORT } \\
\hline & ET & ER & ET & ER & ET & ER & ET & ER \\
\hline LUNES & 14 & 12 & 15 & 8 & 9 & 7 & 5 & 4 \\
\hline MARTES & 12 & 10 & 16 & 13 & 9 & 8 & 7 & 7 \\
\hline \begin{tabular}{|l|} 
MIÉRCOLES \\
\end{tabular} & 13 & 10 & 13 & 10 & 9 & 7 & 9 & 6 \\
\hline JUEVES & 12 & 6 & 12 & 9 & 9 & 7 & 6 & 5 \\
\hline VIERNES & 16 & 10 & 11 & 11 & 10 & 8 & 5 & 4 \\
\hline SÁBADO & 12 & 10 & 11 & 10 & 12 & 12 & 6 & 5 \\
\hline DOMINGO & 14 & 12 & 8 & 7 & 9 & 8 & 3 & 3 \\
\hline TOTAL & 93 & 70 & 86 & 68 & 67 & 57 & 41 & 34 \\
\hline $\begin{array}{r}\text { Porcentaje de } \\
\text { retórica en los } \\
\text { enunciados }\end{array}$ & \multicolumn{2}{|c|}{$75,2 \%$} & \multicolumn{2}{|c|}{$79 \%$} & \multicolumn{2}{|c|}{$85 \%$} & \multicolumn{2}{|c|}{$82,9 \%$} \\
\hline
\end{tabular}

ET: enunciados totales.

ER: enunciados retóricos o persuasivos.

La comparación entre periódicos españoles y portugueses permite conocer cuál de estos medios es más apropiado para llevarlo al aula como herramienta didáctica, por incorporar más ejemplos retóricos. Además, la comparación entre países servirá para confirmar si el uso de figuras retóricas en las portadas es más frecuente en un país u otro.

Los periódicos deportivos seleccionados son: Marca, As, Mundo Deportivo y Sport en España; y A Bola, O Jogo y Record en Portugal. Se analizaron un total de 306 enunciados deportivos a través de las portadas de los tres periódicos portugueses ( A Bola, O Jogo y Record). En el caso de los periódicos deportivos españoles se estudiaron 287 enunciados entre As, Marca, Mundo Deportivo y Sport. 


\section{Resultados}

En el caso de los periódicos deportivos portugueses (ver figura 1) hay un elevado porcentaje de enunciados con figuras retóricas o usos retóricos, aunque estos datos podrían ser más acentuados si se compara con las portadas españolas. En España las portadas incluyen menos enunciados, pero son más retóricos -mayor presencia de figuras-. Desde el punto de vista cuantitativo, y sin analizar la retórica sino el número total de enunciados, A Bola (107) es el que más utiliza en su portada, seguido de Record (100) y, después, de $O$ Jogo (99). En cuanto al análisis cualitativo, enunciados o textos con retórica, $O$ Jogo (63) es el periódico portugués que más aprovecha la retórica en sus textos de portada impresa, seguido de Record (62) y A Bola (51).

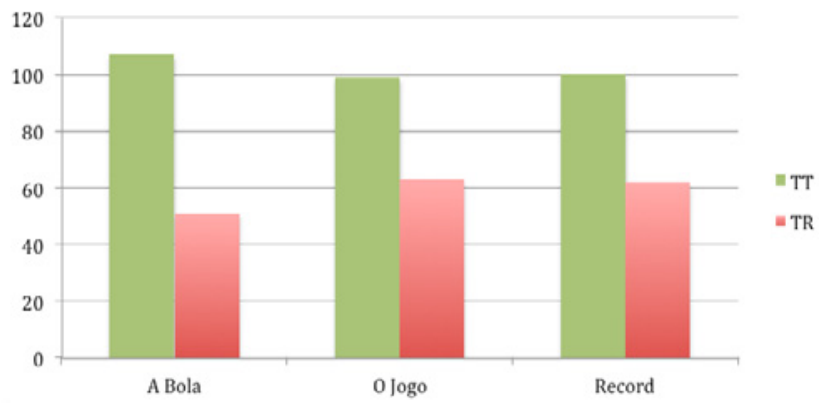

Figura 1. Comparativa Titulares totales y retóricos: Periódicos portugueses. Fuente: elaboración propia

En definitiva, dos tercios de los periódicos portugueses analizados usan mayoritariamente enunciados retóricos en sus portadas impresas (ver figura 1). Solo hay un periódico deportivo, A Bola, donde el porcentaje de uso de la retórica es menor del $50 \%$. Esto puede deberse a que es el diario que más enunciados presenta en su portada y que es más difícil dotar de enunciados cargados de retórica cuanto más abundantes son. Resulta ante todo curioso tratándose del diario deportivo más vendido en Portugal. O Jogo y Record sí que usan más enunciados con figuras retóricas que sin ellas.

En el caso de España (ver figura 2) es mayoritaria la presencia de enunciados retóricos. Sobre la cuantificación de enunciados -sin distinguir los retóricos de los no retóricos-, As es el diario que publica más (93), seguido de Marca (86), Mundo Deportivo (67) y Sport (41). En cuanto a enunciados retóricos, As es el que tiene más (70 enunciados de 93) frente a Marca (68 de 86), Mundo Deportivo (57 de 67) y Sport (34 de 41). Estos resultados tienen que ser matizados, porque la proporción de enunciados retóricos indica que, aunque As es el medio que más enunciados publica en la portada, la cantidad no es sinónimo de calidad. En muchos casos es preferible que exista retórica en todos los enunciados de las portadas, porque la función de estas unidades textuales en la primera página es llamar la atención para que el lector compre el diario en cuestión o lea las noticias que hay en él. Es decir, los enunciados de las portadas deben funcionar como reclamo. En cuanto al periódico que mayor porcentaje de enunciados retóricos publica es Marca que, aunque publica menos enunciados que As, supera al empleado por el resto de periódicos españoles analizados. 


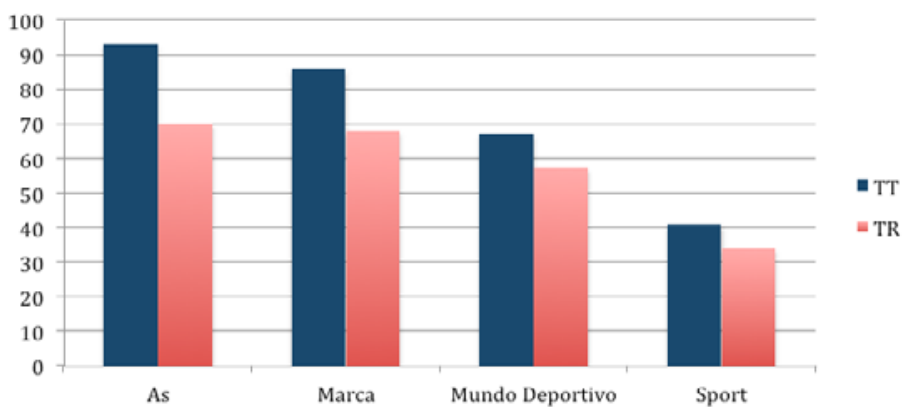

Figura 2. Comparativa Titulares totales y retóricos: Períodicos españoles.

Fuente: elaboración propia

En cuanto a la comparación entre países (figura 3), llama la atención que en las portadas portuguesas haya más texto que en las españolas. Entre los textos portugueses también aparecen frases literales de distintos personajes deportivos. Se supone que estos enunciados también podrían incorporar algún elemento retórico, porque son transcripciones del habla cotidiana, de por sí retórica (Lakoff y Johnson, 1986). En cualquier caso, si comparamos los resultados de uno y otro país, parece que los diarios portugueses podrían publicar más enunciados retóricos en sus portadas impresas para que sus textos fueran más atrayentes, expresivos y/o emotivos para los lectores.

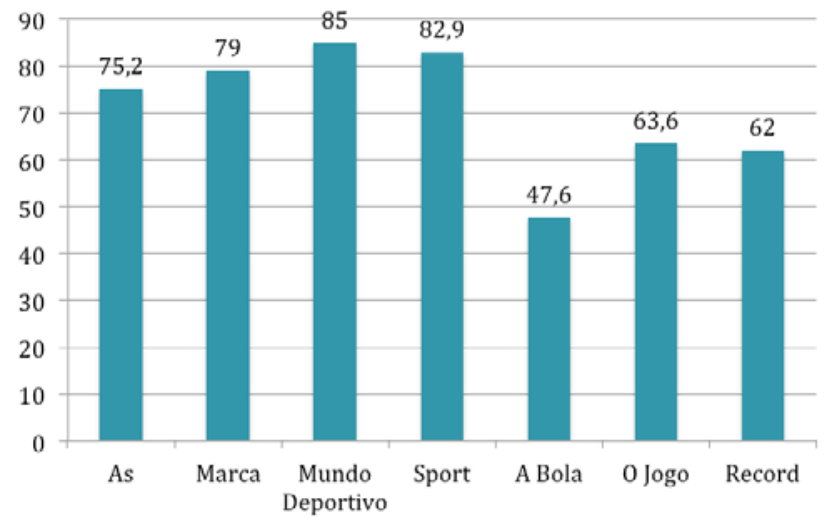

Figura 3. Comparativa Porcentaje de titulares con retórica: periódicos españoles y portugueses. Fuente: elaboración propia

\section{CONCLUSIÓN-DISCUSIONES}

La cantidad de enunciados retóricos encontrados en el análisis de los siete periódicos deportivos permite afirmar la idoneidad del lenguaje deportivo en el aula de lengua y literatura, al menos para mostrar esos ejemplos de creatividad literaria, adorno de los textos y expresividad/emotividad del discurso. Algunos autores (De La Hera Conde- 
Pumpido, Limia Fernández, López García, Toural Bran, 2009); Lopes Martins, 2008) ya han analizado los periódicos deportivos de España y Portugal, pero no se han centrado en su potencial educativo ni han abordado el análisis de elementos retóricos.

Otros estudios cuantifican las figuras retóricas para identificar textos o enunciados retóricos, al igual que se ha hecho en el presente trabajo, pero estos estudios (Quintero Ramírez, 2013; Naranjo de Arcos, 2011; Guerrero Salazar, 2002) no analizan los periódicos deportivos de España y Portugal, y están lejos de proponer una secuencia de actividades para abordar estos contenidos en el aula.

Esta investigación guarda cierta similitud con el de Teruel Planas (1991) en cuanto al análisis de los textos periodísticos para encontrar figuras retóricas. Su estudio solo analiza la metáfora. En un estudio anterior (Suárez y Suárez, 2016) se pone el foco en la presencia de distintas figuras retóricas en el titular deportivo, pero no se analiza la portada impresa ni se estudia ni compara la prensa de los dos países para, después, aprovechar los datos en una secuencia de actividades.

Los resultados del análisis realizado a través de los enunciados en las portadas impresas reafirman la teoría de Núñez y Casasús (1991), que apuntan una estrecha relación entre retórica y periodismo (la intención retórica que acompaña la construcción de cualquier texto). También Teruel Planas (1991) afirma que los textos periodísticos, al articularse como discurso, necesitan del empleo de la retórica para conseguir los fines que persigue: informar, comunicar y persuadir.

La presencia de la retórica en la prensa impresa ya ha sido estudiada por Martínez Hernando (1990) y apunta a la economía del espacio, la captación interés, el contagio de otros contextos léxicos o la voluntad de estilo como posibles causas de esa presencia retórica (1990: 175-179). No obstante, no ha abordado esta cuestión en la prensa específica o especializada, como la deportiva, ni propone cómo llevar estos recursos retóricos al aula. Guerrero Salazar (2007) sí que menciona explícitamente la prensa deportiva como foco de creatividad lingüística, destacando algunos ejemplos que podrían aprovecharse en el aula. Sin embargo, no analiza específicamente las portadas ni propone actividades didácticas concretas.

En una tesis doctoral dedicada a los periódicos digitales o cibermedios (Suárez Ramírez, 2015) se analizaron más de 4000 titulares repartidos entre los cuatro periódicos deportivos españoles que se han utilizado también para este trabajo. Se comprobó que las figuras retóricas que más aparecían eran la hipérbole, la personificación, la metáfora y la metonimia.

Como conclusión, se puede afirmar que las portadas de los periódicos deportivos contienen una elevada presencia de elementos retóricos en sus enunciados y, por ello, deben convertirse en ejemplos para explicar cómo construir un texto, para enseñar qué es importante incluir en la redacción de un texto, para que el lector se sorprenda y se motive al leer.

Para concretar esta apuesta por los textos deportivos y la retórica es preciso proponer una sesión de actividades didácticas que sirvan de ejemplo para su aplicación en las aulas de Educación Primaria y Secundaria. Barros y De Molina (1991) ya propusieron la prensa deportiva como eje temático-motivador para la enseñanza y aprendizaje de español como lengua extranjera. La diferencia entre aquel estudio y este consiste en que las actividades propuestas por estos autores se centraban en la 
metáfora, las frases hechas, los errores o las imprecisiones destinadas a alumnos que están aprendiendo español como lengua extranjera o segunda lengua. En cambio, este trabajo propone que los ejemplos extraídos del estudio y análisis sean los textos para enseñar y aprender cómo funcionan las distintas figuras retóricas.

\title{
Propuesta didáctica
}

Todas las actividades propuestas utilizan enunciados que forman parte de la muestra analizada En las actividades se incluyen breves explicaciones, según el contenido o figura retórica que se vaya a trabajar.

\section{Actividades}

La hipérbole o exageración es uno de los recursos retóricos más utilizados para llamar la atención del receptor.

ACTIVIDAD 1. Con tu compañero, buscad cuatro textos que contengan hipérboles o alteraciones exageradas de la realidad en alguno de los siguientes periódicos digitales deportivos:

\author{
http://www.as.com/ \\ http://www.marca.com/ \\ http://www.sport.es/ \\ http://www.mundodeportivo.com/ \\ http://www.abola.pt/ \\ http://www.ojogo.pt/ \\ http://www.record.pt/
}

ACTIVIDAD 2. En los siguientes textos de la prensa deportiva digital pueden encontrarse alteraciones exageradas de la realidad.

\author{
BOMBO ATÓMICO (Mundo Deportivo) \\ GOL DE ORO (As) \\ SE GANA CUANDO ELLOS QUIEREN (Marca) \\ O MUNDO DE MITROGLOU (A Bola) \\ SOARES DEU-NOS DORES DE CABEÇA (O Jogo)
}

a) En tu opinión, ¿qué está exagerando cada texto?

b) En parejas. Con tu compañero pensad en otras frases típicas de vuestra vida diaria que contengan hipérboles. Compartid los ejemplos que se os ocurran con el resto de la clase.

Las metáforas y las metonimias son dos de las figuras retóricas que más se utilizan en el día a día (Lakoff y Johnson, 1986). De hecho, es algo habitual en cualquier discurso cotidiano oral. Se utiliza la expresión "qué guerra" para referirse a otra persona con la que se discute. También se dice "beber vino" cuando en realidad se podría mencionar la cantidad exacta de este líquido, no referirse a algo tan general. Todos estos casos utilizan palabras que designan un concepto próximo al que se pretende re- 
ferir, pero no exacto. Con esto se invita a pensar, sorprendiendo tanto a lectores como a oyentes. Todas son fórmulas que sirven para prestar atención al emisor del mensaje.

ACTIVIDAD 3. Observa los siguientes titulares de prensa deportiva digital.

- ¿Qué significado tienen para ti las palabras subrayadas?

- ¿A qué se está refiriendo cada palabra en el contexto del titular?

$$
\begin{aligned}
& \text { "BOLAS ARDIENTES" (Marca) } \\
& \text { "BAYERN-MADRID. UN TRUENO EN LOS CUARTOS" (As) } \\
& \text { "VIA } \underline{A Z U L " ~(O ~ J o g o) ~}
\end{aligned}
$$

ACTIVIDAD 4. Metáforas y metonimias escondidas en titulares deportivos:

a) Señala los titulares que no contenga metáforas ni metonimias.

b) Subraya las metáforas y metonimias que encuentres. ¿Hay algún titular que contenga las dos figuras al mismo tiempo?

c) Escoge dos de las metáforas que has señalado y explica a qué se está refiriendo realmente.

MARCA

"SE GANA CUANDO ELLOS DICEN"

"EL CALDERÓN NUNCA FALLA"

"OBLAK PUSO LA GUINDA"

RECORD

"VENHAM MAIS 4"

"FEJSA KO"

"PIZZI E MAIS 10"

"STOP"

\author{
AS \\ "EL LÍDER ES SERGIO RAMOS" \\ "REGRESA EL NIÑO" \\ "A POR ELLOS" \\ O JOGO \\ "SOARES DEU-NOS DORES DE CABEÇA" \\ "CENARIO COR DE ROSA" \\ "EUROPA SORRIU AOS CENTRAIS"
}

La personificación es otro de los recursos (o figuras retóricas) que sirven para hacer más atractivo nuestro discurso oral y escrito.

ACTIVIDAD 5. Observa los siguientes textos deportivos, ¿hay alguna mención a algún animal para referirse a seres humanos -personificación-?

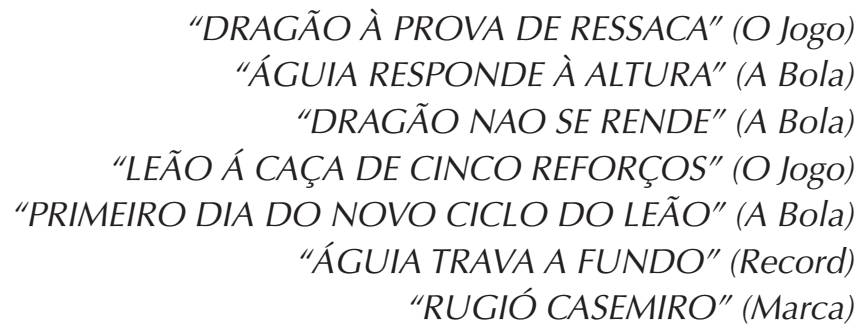


a) Según tu punto de vista, ¿qué son las personificaciones? (ACTIVIDAD INDIVIDUAL)

NOTA: la prensa deportiva portuguesa suele referirse a los equipos de fútbol por sus mascotas o símbolos, que coinciden con animales: "dragones" para referirse a los jugadores o seguidores del Porto, "águilas" para el Benfica y "leones" para el Sporting.

b) Inventa tres titulares de prensa, deportivos o no, que atribuyan particularidades humanas a seres inanimados. Por ejemplo: "El partido del año duerme al Camp Nou" o "Con Vichy las arrugas se camuflan". También puedes dar a una persona cualidades animales (animalización). Ejemplo: "Rugió Casemiro".

La gran cantidad y diversidad de figuras retóricas que aparecen en los textos periodísticos (Suárez Ramírez, 2015) crean una serie de juegos periodísticos, de juegos de palabras o del lenguaje, también juegos periodísticos (Martínez Hernando, 1990; Guerrero Salazar, 2007), que son muy utilizados para la construcción de nuestros discursos orales y escritos. Esa finalidad o apariencia lúdica de estas combinaciones de palabras o de letras, invita al lector y al oyente a mantener la atención en nuestro discurso.

ACTIVIDAD 6. ¿Podrías explicar de qué forma juegan con el lenguaje los siguientes textos deportivos? ¿Qué hacen para captar nuestra atención? ¿Conoces más ejemplos? (ACTIVIDAD INDIVIDUAL)

Salvad al soldado Keylor (Marca, 14 de marzo de 2017)

Ganar o Ganar (Sport, 19 de marzo de 2017) Bombo atómico (Mundo Deportivo, 16 de marzo de 2017)

Regresa el Niño (As, 15 de marzo de 2017) Olho por Olho (A Bola, 14 de marzo de 2017) CR7, OK Marco, KO (Record, 19 de marzo de 2017)

Via Azul (O Jogo, 19 de marzo de 2017) Por todo lo alto (Marca, 18 de marzo de 2017)

\section{REFERENCIAS BIBLIOGRÁFICAS}

Albadalejo Mayordomo, T. (2005). Retórica, comunicación, interdiscursividad. Revista de investigación lingüística, VIII, 7-33.

Alcoba López, A. (2005). Periodismo deportivo. Madrid, España: Síntesis.

Alvar Ezquerra, M. (1999). El léxico nuevo en los medios de comunicación. En P. Carbonero, M. Casado y P. Gómez Manzano (Coords.), Lengua y discurso. Estudios dedicados al profesor Vidal Lamíquiz (pp. 125-144). Madrid. España: Arco Libros.

Assumpção, Z. (1999). Radioescola: uma proposta para o ensino de primeiro grau. São Paulo, Brasil: Annablume.

Ayala Payet, A. (1994). Talleres de radio escolar, cultural y juvenil. Comunicar, 3, 50-64.

Barros García, P. y De Molina, J. A. (1991). El uso de la lengua en la prensa deportiva: aportaciones para la enseñanza/aprendizaje del E/LE. Actas del III Congreso Nacional de ASELE. Málaga, España.

Bühler, K. (1950). Teoría del lenguaje. Madrid: Revista de Occidente. 
Brandão Pinheiro, M. C. (1996). Os media e o desporto. Análise dos géneros masculino e feminino nos jornais desportivos. Actas do III Congresso Português de Sociologia.

Caldas, G. (2006). Mídia, Escola e leitura crítica do mundo. Revista Educação e Sociedade, 27, 117-130.

Carr, N. (2011). Superficiales. ¿Qué está haciendo Internet con nuestras mentes? Madrid: Taurus.

Núñez Ladevéze, L. y Casasús Guri, J. M. (1991). Estilo y géneros periodísticos. Madrid: Ariel.

Castañón Rodríguez, J. (2006a). Idioma y Deporte. El idioma español en la prensa deportiva. Recuperado de http://www.idiomaydeporte.com/articulos/el-idiomaespanol-en-la-prensa-deportiva-400108.php.

Castañón Rodríguez, J. (2006b). El léxico periodístico del deporte: las palabras en juego. Revista Digital efdeportes.com, 111. 1-1. Recuperado de http://www.efdeportes.com/efd101/lexico.htm.

Cuvardic García, D. y Vargas Castro, E. (2010). Recursos lingüísticos en la titulación periodística costarricense: el caso de La Nación y el diario La Extra. Filología y Lingüística, 36, 207-232.

De La Hera Conde-Pumpido, T., Limia Fernández, M., López García, X. y Toural Bran, C. (2009). La participación en los diarios digitales europeos (España, Italia, Portugal y Francia). Trípodos, 637-645.

Fidalgo, J. (2000). Novos desafíos para a imprensa escrita e para o jornalismo. En M. Pinto (Coord.), A Comunicação e os Media em Portugal. Cronologia e leitura de tendências. Braga: Universidade do Minho.

Freinet, C. (1974). O Jornal Escolar. Lisboa: Estampa.

Galindo Merino, M. (2016). Nuevos horizontes en la enseñanza de E/LE. Enseñar español a través del deporte. Hesperia, Anuario de filología hispánica, 2, 13-27.

García Molina, E. T. (2002). Deporte y metáforas. Influencia del lenguaje deportivo en la vida cotidiana. Madrid: Ministerio de Educación, Cultura y Deporte. Serie ICd.

Garrido Gallardo, M. A. (1994). Musa de la retórica. Problemas y métodos de la ciencia de la literatura. Madrid: CSIC.

Guerrero Salazar, S. (1999). La función poética en el lenguaje futbolístico. Isla de Arriarán, Revista Cultural y Científica, 14, 461-469.

Guerrero Salazar, S. (2002). Lenguaje deportivo, entre coloquial y literario. Isla de Arriarán, Revista Cultural y Científica, 19, 365-382.

Guerrero Salazar, S. (2007). La creatividad en el lenguaje periodístico. Madrid: Cátedra. Hernández Alonso, N. (2003). El lenguaje de las crónicas deportivas. Madrid: Cátedra. Jakobson, R. (1958). La lingüística y la poética. En N. E. Enkvist (Ed.), Lingüística y estilo (pp. 123-173). Madrid: Cátedra.

Jiménez Martínez (2001). La radio en la escuela. Contextos educativos, 4, 297-313.

Knapé, J. (2003). Persuasion. HWRh, 6, 874-907.

Maingueneau, D. (1999). Analysing self-constituting discourses. Discourse Studies, 1, 175-199.

Martínez Hernando, B. (1990). Lenguaje de la prensa. Madrid: Eudema.

Martín Vegas, R. A. (2009). Manual de Didáctica de la Lengua y la Literatura. Madrid: Síntesis. 
Medina Cano, F. (1995). Los narradores deportivos y sus epopeyas cotidianas. Estudios sobre las culturas contemporáneas, 2, 69-106.

Mcluhan, M. (1974). El aula sin muros. Barcelona: Laia

Morán, J. M., Masetto, M. y Behrens, M. (2006). Novas tecnologías e Mediação pedagógica. Campinas, Brasil: Papirus.

Naranjo de Arcos, A. (2011). Tratamiento de la información deportiva en la prensa: la crónica como género prevalente. El caso de los encuentros de fútbol entre Real Madrid y F.C. Barcelona (tesis doctoral). Universidad de Málaga. España.

Lacalle Medina, J. M. (1997). Orígenes de la prensa deportiva en España. Historia 16, 253. 76-83.

Lakoff, G. y Johnson, M. (1986). Metáforas de la vida cotidiana. Madrid: Cátedra.

Lázaro Carreter, F. (1994). El español en el lenguaje deportivo. En A. Gómez Font (Ed.), El idioma español en el deporte (pp. 19-35). Madrid: Fundación EFE.

Lopes Martins, H. M. (2008). Imprensa Desportiva: Uma análise comparativa entre Portugal, Espanha e Itália (tese de mestrado). Setúbal: Instituto Politécnico.

Oliva Marañon, C. (2012). Lenguaje deportivo y comunicación social: prototipo coetáneo de masas. Revista de comunicación de la SEECI, 28, 11-29.

Quintana Garzón, R. (2001). El lenguaje de la radio y sus posibilidades educativas. Comunicar, 17, 97-101.

Quintero Ramírez, S. (2013). Análisis sintáctico de titulares deportivos en la versión electrónica de seis periódicos mexicanos. Lengua y Habla, 17, 165-182.

Rodesiler, L. (2016). Sports-based Text Sets: Fostering Critical Literacy at the Intersections of Sport and Society. The Clearing House: A Journal of Educational Strategies Issues and Ideas, 0, 1-6.

Robrieux, J. (1993). Éléments de rhétorique et d'argumentation. París: Dunod.

Salaverría Aliaga, R. (2005). Redacción periodística en Internet. Pamplona: Eunsa.

Salaverría Aliaga, R. y Díaz Noci, J. (Coord) (2003). Manual de redacción ciberperiodística. Barcelona: Ariel.

Sitman, R. (2004). Más allá de la información: la prensa en la enseñanza de ELE. Actas XIV Congreso ASELE, Burgos 2003, (pp. 96-108). Burgos: Universidad de Burgos.

Sobrados, M. (2005). Entre la información y la opinión. Una revisión de los principales géneros en el periodismo deportivo. En J. Marín Montín (Coord.), Comunicación y deporte. Nuevas perspectivas de análisis (pp. 184-201). Sevilla: Comunicación Social.

Spang, K. (2005). Persuasión: fundamentos de retórica. Navarra: Eunsa.

Suárez Muñoz, A. (1992). Desarrollo de la comprensión lectora a través del uso didáctico del periódico. Campo Abierto, 9, 11-42.

Suárez Ramírez, S. (2015). Los titulares en los cibermedios deportivos. Principales figuras retóricas y su aplicación didáctica (tesis doctoral). Universidad de Extremadura.

Suárez Ramírez, S. y Suárez Muñoz, A. (2016). La retórica del titular deportivo. Revista Documentación de las Ciencias de la Información, 39, 83-116.

Teruel Planas, E. (1991). Informació i Metáfora: pluralitat retórica i construcció de la realitat (tesis doctoral). Universidad Autónoma de Barcelona.

Van Dijk, T. A. (1990). La noticia como discurso. Comprensión, estructura y producción de la información. Barcelona: Paidós. 


\section{ANEXo I. EJEMPLO de CORPUS}

Enunciados de mayor tamaño en las portadas. Solo se ha seleccionado uno por portada/periódico porque el corpus total del trabajo era ingente e imposible de recoger en el presente documento.

\section{Leyenda}

$\mathbf{1}=13$ de marzo;

2=14 de marzo;

$3=15$ de marzo;

$4=16$ de marzo;

$\mathbf{5 = 1 7}$ de marzo;

$\mathbf{6}=18$ de marzo;

7=19 de marzo.

\section{SPORT}

1. SON HUMANOS

2. BARÇA Y BELLERÍN NEGOCIAN

3. UNZÚE GANA ENTEROS

4. MBAPPÉ ENAMORA AL BARÇA

5. NADIE QUIERE AL BARÇA

6. RESPETO Y ALIVIO

7. GANAR O GANAR

\section{MUNDO DEPORTIVO}
1. RESACA
2. VERRATI A TIRO
3. DEMBELE REACTIVADO
4. BOMBO ATÓMICO
5. NI MADRID NI ATLÉTICO
6. MAMMA MIA
7. VERRATI O COUTINHO

\section{RECORD}

1. ATAQUE AO TETRA

2. VENHAM MAIS 4

3. WELTHON. SPORTING NEGOCEIA

4. NAO PONHAM PRESSAO

5. FEJSA KO

6. PIZZI E MAIS 10

7. STOP

\section{MARCA}

1. SE GANA CUANDO ELLOS DICEN

2. SALVAD AL SOLDADO KEYLOR

3. EL CALDERÓN NUNCA FALLA

4. OBLAK PUSO LA GUINDA

5. BOLAS ARDIENTES

6. POR TODO LO ALTO

7. RUGIÓ CASEMIRO

\section{AS}

1. EL LIIDER ES SERGIO RAMOS

2. SERGIO RAMOS. HA DADO 9 PUNTOS

3. REGRESA EL NIÑO

4. TRIPLETE ESPAÑOL

5. A POR ELLOS

6. BAYERN-MADRID. UNTRUENO EN LOS CUARTOS

7. GOL DE ORO

\section{A BOLA}

1. O MUNDO DE MITROGLOU

2. OLHO POR OLHO

3. UM ADEUS ANUNCIADO

4. VIEIRA E JESUS SENTARAM-SE A MESMA MESA

5. A UMA VITORIA DE FAZER HISTORIA

6. AVISO AMARELO

7. PASSO ATRÁS

\section{O JOGO}

1. SOARES DEU-NOS DORES DE CABEÇA

2. CENARIO COR DE ROSA

3. É A JUVE E MAIS DEZ

4. EUROPA SORRIU AOS CENTRAIS

5. JOTA É PARA SEGURAR

6. DRAGAO A PROVA DE RESSACA

7. VIA AZUL 